\title{
Paper
}

\section{An Experimental Research on Surface Roughness of Fine-Grained Graphite Machined by Micro End Mills}

\author{
Hua QIU*† Member, AkIO KubO ${ }^{\dagger}$ Member
}

(Received March 24, 2020, revised July 6, 2020)

\begin{abstract}
This paper presents an experimental research on surface roughness of fine-grained graphite machined by micro milling. POCO EDM-3 and POCO EDM-AF5 fine-grained graphite were adopted as workpiece material. A full groove milling was performed respectively using a tungsten carbide end mill with or without diamond-coating dedicated to graphite cutting. EDM-AF5, which has a smaller grain size than EDM-3, showed better property for surface roughness. The diamond-coated tool demonstrated more excellent abilities for micro milling than the uncoated tool, to achieve more beautiful machining surface under higher cutting speed and feed rate condition. The influence degree of the grain size and the cutting parameters including cutting speed, feed rate and cutting depth on surface roughness was analyzed by using ANOVA method. The analysis results proved that the feed rate and the grain size have the most significant influence and the cutting depth only has a minor effect on the surface roughness, while the cutting speed is not an influence factor. Regression equations to predict the surface roughness value from related factors were derived with the regression analysis. Through additional verification experiments, the effectiveness of these equations was also confirmed.
\end{abstract}

Keywords: Fine-grained graphite, Micro milling, Surface roughness, ANOVA, Regression analysis,

\section{Introduction}

In recent years, the trend in reducing the size and increasing the integration level of various devices and products has significantly encouraged a development of metal processing for miniaturization and high precision [1] [2]. Micro electrical discharge machining (micro EDM) is a technology that gets a lot of attention for manufacture of miniature parts with complex 3D shape, especially suitable for accurate and efficient fabrication of micro dies, molds and tools made of difficult-to-machine materials in a small batch production [3] [4]. In such situation, it is an important core technique how to manufacture the electrodes for processing these micro parts with high precision and efficiency [5] [6]. Since the difficulty of electrode fabrication is directly affected, not only good electrical discharge machining characteristics but also excellent processability are required for microelectrode materials [5] [7]. Fine-grained graphite has many advantages such as high material removal rate, high heat resistance and temperature strength, good machinability and relatively low price, so its application as electrode material for micro die sinking EDM has been rapidly spreading in recently [8] [13].

On the other hand, to achieve high quality of micro EDM workpieces, the finishing of electrode surface is an important element. The quality of the electrode surface is directly related to its processing conditions. Graphite is a

\footnotetext{
* Corresponding: chiu@ip.kyusan-u.ac.jp

$\dagger$ Kyushu Sangyo University

2-3-1, Matsukadai, Higashi-ku, Fukuoka City, Japan 813-8503
}

typical brittle material, so in the machining, the factors to affect the roughness of machined surface not only include cutting parameters such as cutting speed and feed rate, but also the crystal grain size is more important one. However, up to now, the researches on fine-grained graphite cutting processing have mainly focused on tool wear and tool life [14] [16], chip formation mechanism [17] [19], and so on. There were few studies on the surface finishing quality published [20] [22]. Moreover, in these limited studies, the different types of graphite material and tool were adopted, and the values of the cutting parameters tested were respectively restricted to a relatively narrow range; Especially, the graphite material dealt with in every study had only one grain size which differed from one another, all sizes tested were equal to or larger than $5 \mu \mathrm{m}$ thus they may not be suitable for micro engraving electrodes [23]. As a result, the obtained conclusions seem to be inconsistent and contradictory with each other. For example, as the most important factor to affect the surface roughness of machined graphite, Reference [20] concluded with the feed rate but References [21] and [22] claimed to include the cutting speed as well.

Therefore, in assuming the processing of electrode with complex shape for micro EDM, the purpose of this research aims at examining and analyzing the characteristics of the surface roughness in fine-grained graphite milling. The graphite materials with different grain size are machined by different micro end mills under cutting conditions over a wide range. In order to confirm the influence degree of each tested cutting parameter and grain size on surface roughness, the experimental results are evaluated using the anal- 
Table 1: Typical values of fine-grained graphite materials.

\begin{tabular}{ccc}
\hline & EDM-3 & EDM-AF5 \\
\hline Average grain size & $<5 \mu m$ & $<1 \mu m$ \\
Flexural strength & $93.1 \mathrm{MPa}$ & $117.6 \mathrm{MPa}$ \\
Compressive strength & $147 \mathrm{MPa}$ & $186.2 \mathrm{MPa}$ \\
Hardness & $\mathrm{HS} \mathrm{76}$ & $\mathrm{HS} 87$ \\
Electrical resistivity & $14 \mu \Omega m$ & $17 \mu \Omega m$ \\
\hline
\end{tabular}

Table 2: Specifications of end mills.

\begin{tabular}{ccc}
\hline & DIA tool & GF tool \\
\hline Carbide material & \multicolumn{2}{c}{ Equivalent to K10 carbide[24] } \\
Coating material & Diamond film & Non-coating \\
Diameterr & \multicolumn{2}{c}{$2 \mathrm{~mm}$} \\
No. of flute & \multicolumn{2}{c}{2} \\
Helix angle & $35^{\circ}$ & $30^{\circ}$ \\
Flute length & $6 \mathrm{~mm}$ & $10 \mathrm{~mm}$ \\
Shank diameter & \multicolumn{3}{c}{$4 \mathrm{~mm}$} \\
\hline
\end{tabular}

ysis of variance (ANOVA) method. And the same time, the related experimental equations, to predict the surface roughness from the values of cutting parameters and grain size according to each end mill, are obtained by the regression analysis method, too. Furthermore, the validity of the regression equations is examined and discussed through additional verification experiments.

\section{Experimental Method and Equipment}

In this research, two types of isotropic fine-grained (ultrafine grain) materials, EDM-3 for fine detailed electrodes and EDM-AF5 for fine detailed engraving electrodes, provided by POCO Graphite, Inc. were adopted as workpiece material. Table 1 shows their main physical property data [23]. Two types of tungsten carbide square end mills dedicated to graphite cutting in diameter of $2 \mathrm{~mm}$ were used for machining workpiece. One is coated with ultramicrocrystalline diamond film on carbide surface and the other is a non-coating. The former is called as DIA tool and the latter as GF tool in the following. Table 2 shows the main specifications of both tools.

Experiments were carried out on a vertical type of machining center (MC, Wasino WMC-4) in dry cutting process. Figure 1 illustrates the set-up of processing equipment. During the experiment, the main spindle of MC was locked, on which a high-speed spindle with independent driving unit (Nakanishi HES810) was mounted. An end mill was clamped by the collet chuck of the high-speed spindle. On the other hand, the motion of MC table was controlled by NC program and the workpiece fixed on the table was cut by the end mill in a rotational speed pre-set on the driving unit. A special industrial vacuum cleaner was

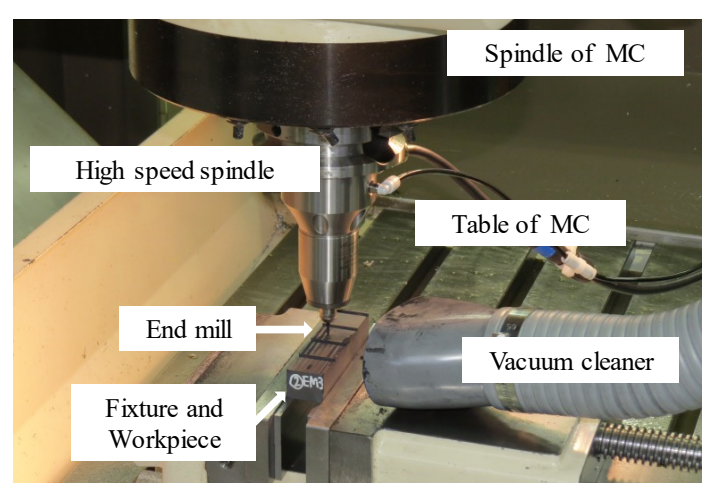

Figure 1: Experimental set-up for workpiece milling.

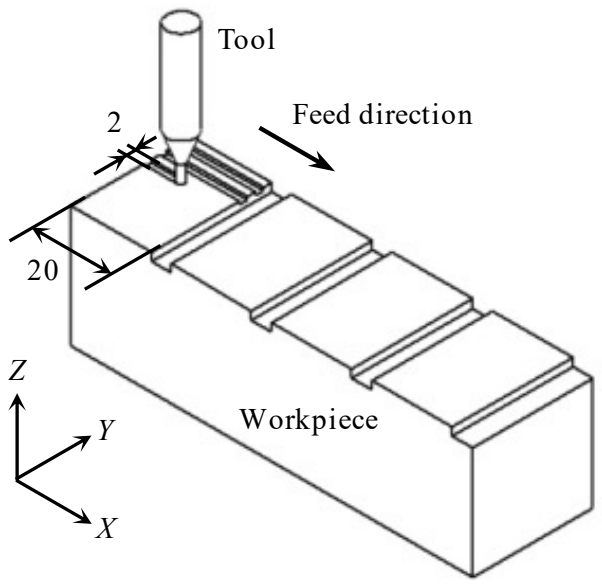

Figure 2: Workpiece contour.

adopted to prevent scattering of dust-like chips generated during cutting process.

The cutting experiments were performed in full immersion groove milling as shown in Fig. 2. The groove sizes were $2 \mathrm{~mm}$ for width and $20 \mathrm{~mm}$ for length, and the direction was set along the X-axis direction of MC. Three parameters, cutting speed, feed rate and cutting depth (axial depth of cut, i.e. the depth of machined groove), were respectively set to three levels for each tool. The values of the intermediate level for each parameter all were fixed at the value recommended by the tool manufacturer. Because of a total of 27 combinations for cutting conditions, 27 grooves were arranged on one workpiece, and the processing of each cutting condition was performed in order. This process was repeated three times, and thus three workpieces made of the same material were machined by the same tool under the same conditions. Table 3 summarizes the cutting conditions adopted.

The workpiece surface was measured using a surface roughness measuring machine (Tokyo Seimitsu 470A) and

Table 3: Cutting parameters.

\begin{tabular}{cccc}
\hline & Cutting speed $v(\mathrm{~m} / \mathrm{min})$ & Feed rate $f(\mu \mathrm{m} /$ tooth $)$ & Cutting depth $t(\mathrm{~mm})$ \\
\hline DIA tool & $125.7,188.5,251.4$ & $2,5,10$ & $0.1,0.2,0.5$ \\
GF tool & $37.7,50.3,62.8$ & & \\
\hline
\end{tabular}



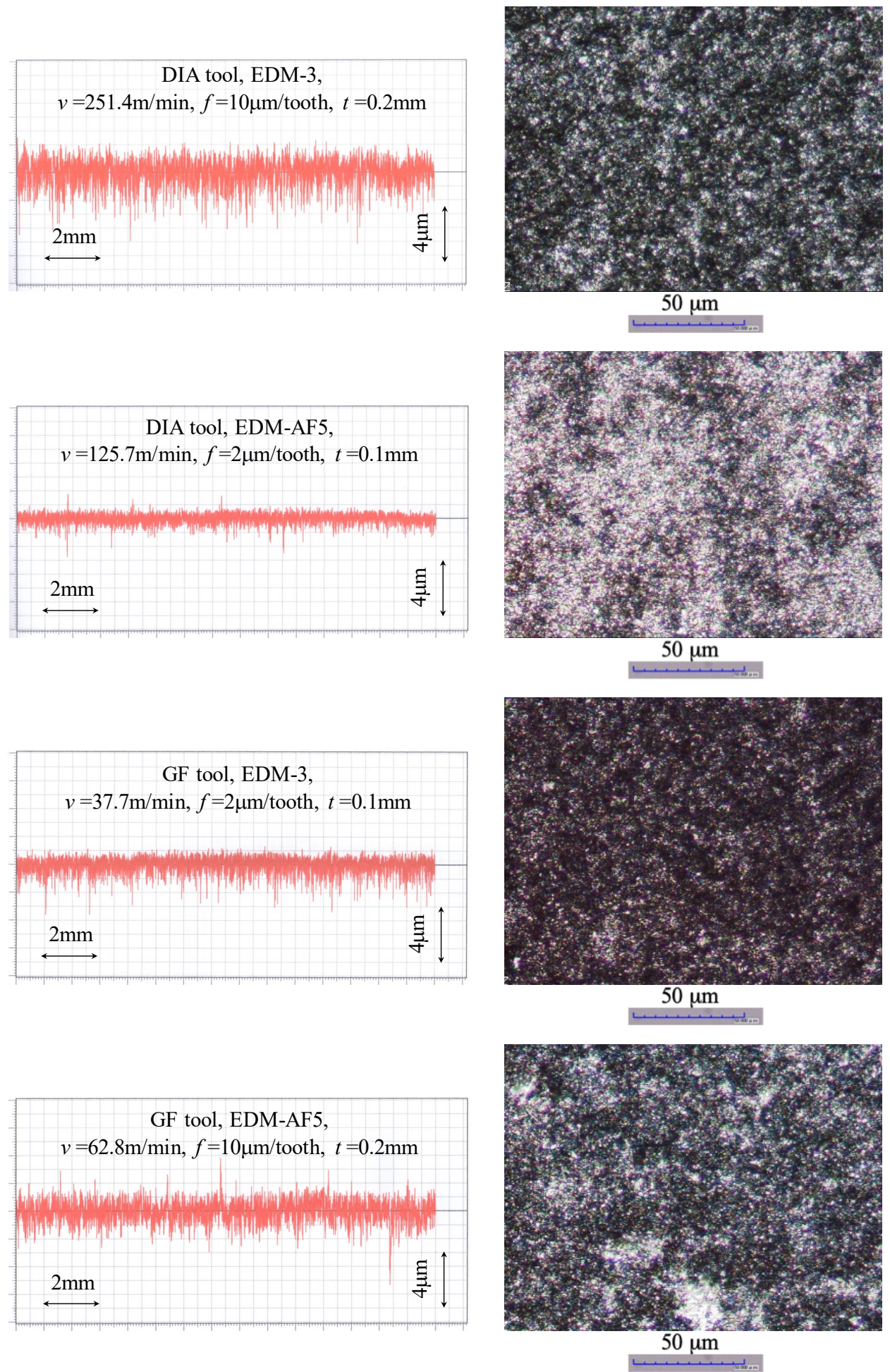

Figure 3: Examples of the profile curve and micrograph of machined workpiece surface.

presented as the arithmetical mean deviation of roughness, $R_{a}$ value in $\mu \mathrm{m}$. The measuring direction is the same as the feed rate, and the measurement position was located near the central place of workpiece groove bottom. Moreover, the surface texture of groove bottom was observed using a 3D digital fine scope (OMRON VC7700), and the pictures of microstates were taken and recorded.

\section{Experimental Results}

Figure 3 illustrates examples of the surface profile curve of machined workpiece by the surface roughness measuring machine together with the corresponding micrographs by the $3 \mathrm{D}$ digital fine scope. Using the automatic evaluation function of the measuring machine, the arithmetical mean deviation of assessed profile, i.e. commonly called the 

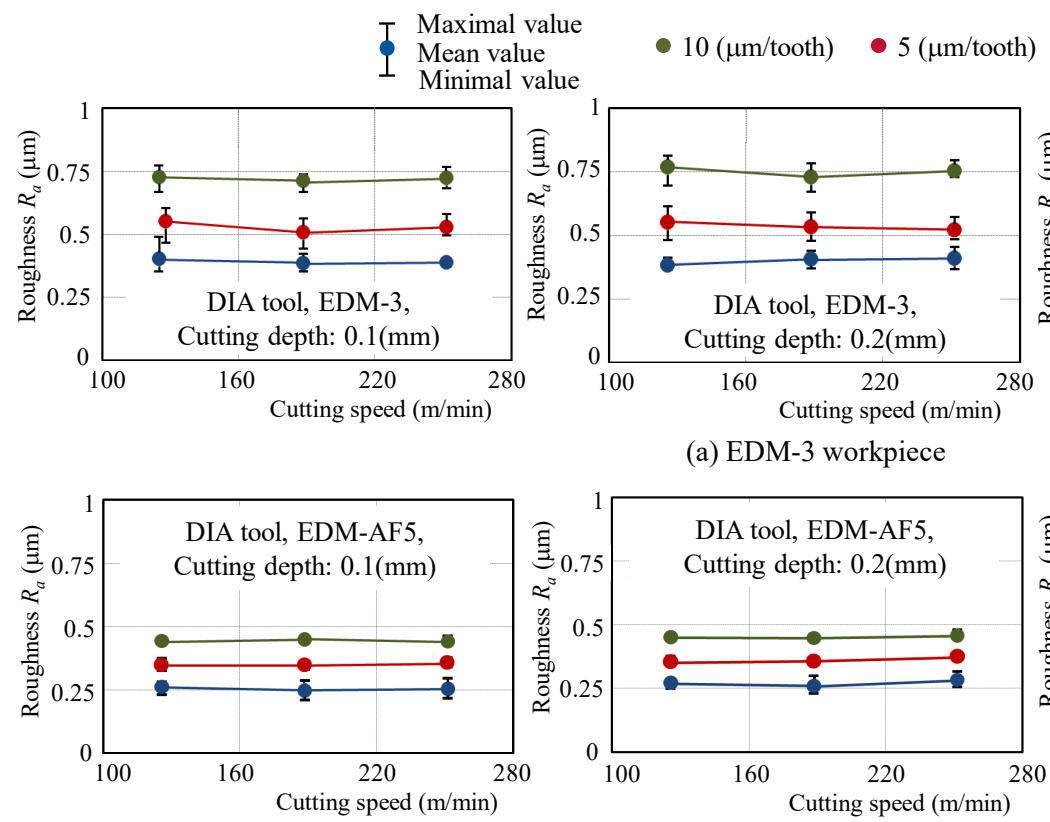

(b) EDM-AF5 workpiece
- $10(\mu \mathrm{m} /$ tooth $) \bullet 5(\mu \mathrm{m} /$ tooth $) \bullet 2(\mu \mathrm{m} /$ tooth $)$
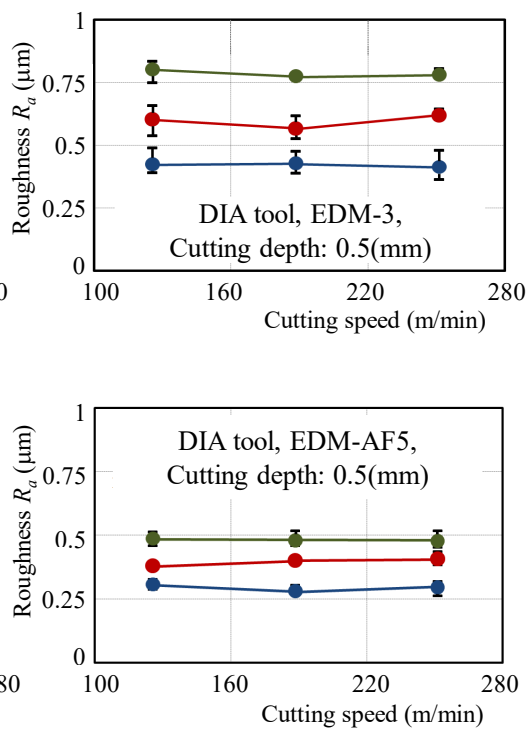

Figure 4: Surface roughness $R_{a}$ of machined workpiece by DIA tool.

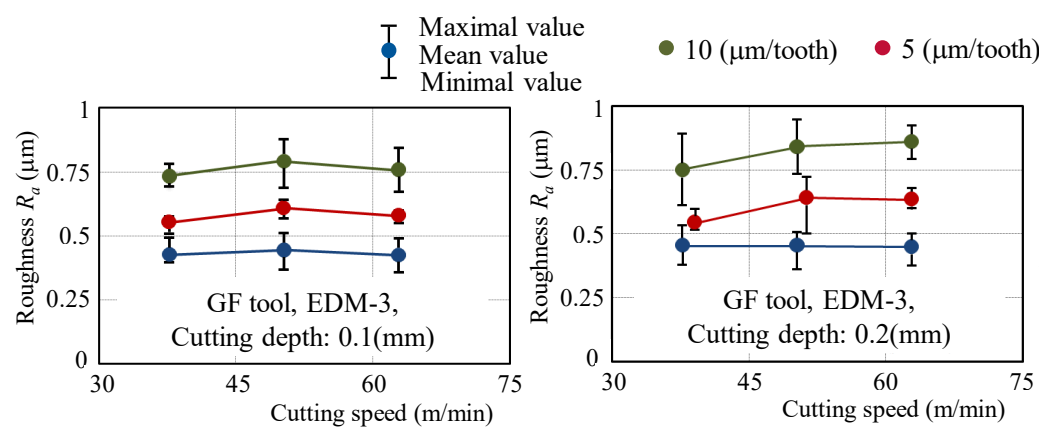

$2(\mu \mathrm{m} /$ tooth $)$

(a) EDM-3 workpiece
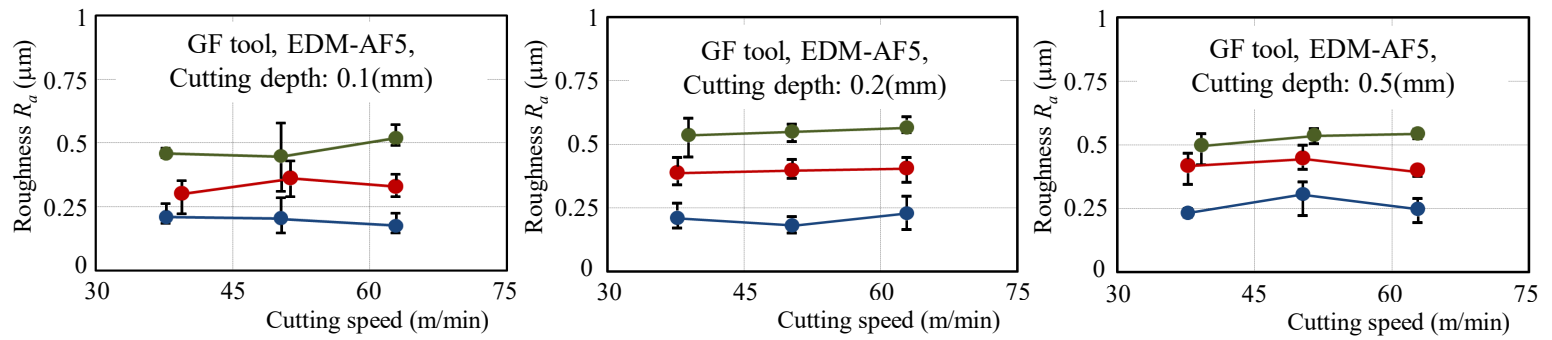

(b) EDM-AF5 workpiece

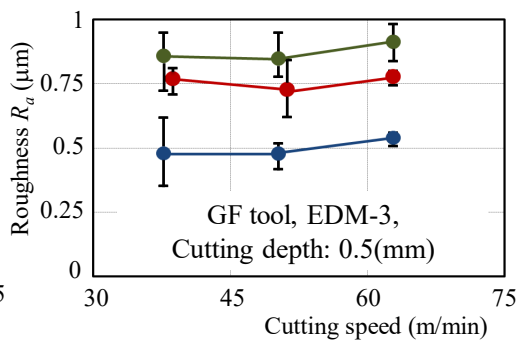

Figure 5: Surface roughness $R_{a}$ of machined workpiece by GF tool.

average value of surface roughness, $R_{a}$ value, is extracted from the surface profile curves. As shown in the surface micrographs, the machined surfaces are quite smooth, no feed marks like mentioned in Reference [20] are observed on each groove.

Figure 4 and Fig. 5 summarize the results of the average surface roughness $R_{a}$ of all workpiece grooves respectively machined by DIA tool and GF tool. In the figures, each dot mark indicates a mean value of $R_{a}$ of three grooves cut under the same condition and a coincident bar mark cor- responds to its distribution range. From these figures, the following items can be confirmed.

(a) With the same cutting conditions, EDM-AF5 finegained graphite, which has a smaller grain size than EDM-3 fine-grained graphite, has better surface roughness and less deviation in $R_{a}$ value.

(b) From the standpoint of surface finish and roughness, DIA tool is more suitable than GF tool.

(c) For three cutting parameters examined, the feed rate 
Table 4: ANOVA result for milling roughness of fine-grained graphite using DIA tool.

\begin{tabular}{ccccccc}
\hline Source of variation & Sum of squares & Degree of freedom & Mean square & $F$-value & $P$-value & Contribution ratio $(\%)$ \\
\hline Grain size (A) & 1.666 & 1 & 1.666 & 1135.246 & 0.0000 & 41.422 \\
Feed rate (B) & 1.924 & 2 & 0.9618 & 655.194 & 0.0000 & 47.837 \\
Cutting speed (C) & 0.003981 & 2 & 0.001991 & 1.356 & 0.2620 & 0.099 \\
Cutting depth (D) & 0.06251 & 2 & 0.03125 & 21.290 & 0.0000 & 1.554 \\
AB & 0.1841 & 2 & 0.09203 & 62.690 & 0.0000 & 4.577 \\
AC & 0.001829 & 2 & 0.0009144 & 0.623 & 0.5383 & 0.045 \\
AD & 0.001496 & 2 & 0.0007477 & 0.509 & 0.6023 & 0.037 \\
BC & 0.0008016 & 4 & 0.0002004 & 0.137 & 0.9685 & 0.020 \\
BD & 0.003590 & 4 & 0.0008974 & 0.611 & 0.6554 & 0.089 \\
CD & 0.0004969 & 4 & 0.0001242 & 0.085 & 0.9870 & 0.012 \\
ABC & 0.004893 & 4 & 0.001223 & 0.833 & 0.5069 & 0.122 \\
ABD & 0.002740 & 4 & 0.0006849 & 0.467 & 0.7601 & 0.068 \\
ACD & 0.0006842 & 4 & 0.0001711 & 0.117 & 0.9764 & 0.017 \\
BCD & 0.004196 & 8 & 0.0005245 & 0.357 & 0.9406 & 0.104 \\
ABCD & 0.002501 & 8 & 0.0003127 & 0.213 & 0.9880 & 0.062 \\
\hline Error & 0.1585 & 108 & 0.001468 & & & 3.941 \\
\hline Total & 4.022 & 161 & & & & \\
\hline
\end{tabular}

shows the largest effect on the roughness of machined surface. In contrast, the influence of the cutting depth and the cutting speed is significantly less.

(d) From the experimental results obtained, it cannot be concluded that the cutting conditions recommended by the tool manufacturer are particularly effective for improving the machined surface roughness.

\section{Analysis and Discussion for Experimental Results Based on Statistical Methods}

In this research, in order to quantitatively evaluate the effect of each examined parameter on surface roughness and to determine the influence factors in micro milling of finegrained graphite, the experimental data were analyzed using the ANOVA method. Furthermore, the relationship between the surface roughness and the influence factors was derived through the regression analysis. A general statistical analysis software, SPSS, was utilized for these analysis calculations.

4.1 Results of ANOVA Table 4 and Table 5 show the results of ANOVA on surface roughness $R_{a}$ for DIA tool and GF tool, respectively. The analysis was performed under a condition of considering four parameters, i.e. average grain size $s(\mu \mathrm{m})$ of graphite material, feed rate $f(\mu \mathrm{m} /$ tooth $)$, cutting speed $v(\mathrm{~m} / \mathrm{min})$, and cutting depth $t(\mathrm{~mm})$. However, the analysis results have identified that the cutting speed is not an influential factor at a level of significance of 0.05 ( $P$ value $>0.05)$. Moreover, as can be seen from the values of the contribution ratio in the tables, it was also confirmed that the grain size and the feed rate have a significant effect on the surface roughness, and the effect of the cutting depth was rather smaller. In addition, the effect caused by an interaction between the grain size and feed rate can be confirmed in DIA tool milling.

4.2 Results of the Regression Analysis Based on the ANOVA results mentioned above, the relationship between the arithmetical mean deviation of assessed profile, $R_{a}(\mu$ $\mathrm{m})$, of workpiece surface and the influence factors is defined in the form of Eq. (1).

$$
R_{a}=k f^{m} t^{n} s^{l}
$$

Through a logarithmic transformation operation, the following expression is obtained.

$$
\log _{10} R_{a}=m \log _{10} f+n \log _{10} t+l \log _{10} s+\log _{10} k
$$

Using the linear regression analysis function of SPSS, the values of undetermined coefficients $m, n, l$ and $\log _{10} k$ in the equation can be estimated.

Table 6 shows the results of the regression analysis. The coefficient of determination $R^{2}$ represents the percentage to be predicted by the regression equation with respect to all $R_{a}$ information contained in the experimental results. Therefore, the larger the $R^{2}$ value is, the higher the predication accuracy of the regression equation is [25]. In the case of DIA tool, the agreement degree of the $R_{a}$ values estimated by the regression equation with the corresponding experimental values is $94.3 \%$, and in the case of GF tool, this degree is $87.2 \%$. The reason of a lower agreement degree in the latter is that the $R_{a}$ value of the surface roughness by GF tool presented a larger range of variation, as shown in Fig. 4 and Fig. 5. Moreover, for each combination of cutting condition, the residual of $\log _{10} R_{a}^{(m)}-\log _{10} R_{a}$, where superscript $(m)$ means a measured value and non-superscript is its corresponding value predicted by the regression equation, is calculated and the standard deviation of all residuals, $\sigma$, is 0.0346 for DIA tool and 0.0712 for GF tool.

On the other hand, in order to identify and examine the effect of the cutting speed $v$ again, the relationship between the surface roughness $R_{a}$ value and the influencing factors was assumed in a form of Eq. (3) and the regression analysis was also performed.

$$
R_{a}=k f^{m} t^{n} s^{l} v^{h}
$$


Table 5: ANOVA result for milling roughness of fine-grained graphite using GF tool.

\begin{tabular}{ccccccc}
\hline Source of variation & Sum of squares & Degree of freedom & Mean square & $F$-value & $P$-value & Contribution ratio $(\%)$ \\
\hline Grain size (A) & 2.910 & 1 & 2.910 & 610.855 & 0.0000 & 43.086 \\
Feed rate (B) & 2.868 & 2 & 1.434 & 301.006 & 0.0000 & 42.464 \\
Cutting speed (C) & 0.02726 & 2 & 0.01363 & 2.861 & 0.0616 & 0.404 \\
Cutting depth (D) & 0.2392 & 2 & 0.1196 & 25.104 & 0.0000 & 3.542 \\
AB & 0.02450 & 2 & 0.01225 & 2.571 & 0.0811 & 0.363 \\
AC & 0.003553 & 2 & 0.001777 & 0.373 & 0.6896 & 0.053 \\
AD & 0.03140 & 2 & 0.01570 & 3.295 & 0.0408 & 0.465 \\
BC & 0.01240 & 4 & 0.003101 & 0.651 & 0.6274 & 0.184 \\
BD & 0.03758 & 4 & 0.009396 & 1.972 & 0.1039 & 0.556 \\
CD & 0.005646 & 4 & 0.001412 & 0.296 & 0.8798 & 0.084 \\
ABC & 0.003332 & 4 & 0.0008330 & 0.175 & 0.9509 & 0.049 \\
ABD & 0.02218 & 4 & 0.005546 & 1.164 & 0.3307 & 0.328 \\
ACD & 0.02887 & 4 & 0.007217 & 1.515 & 0.2029 & 0.427 \\
BCD & 0.01535 & 8 & 0.001918 & 0.403 & 0.9169 & 0.227 \\
ABCD & 0.01034 & 8 & 0.001293 & 0.271 & 0.9739 & 0.153 \\
\hline Error & 0.5145 & 108 & 0.004764 & & & 7.618 \\
\hline Total & 6.754 & 161 & & & & \\
\hline
\end{tabular}

Table 6: Regression analysis result for Eq. (1).

\begin{tabular}{ccccccc}
\hline Tool type & $R^{2}$ & Standard error $\sigma$ & $m$ & $n$ & $l$ & $\log _{10} k$ \\
\hline DIA & $94.3 \%$ & 0.0346 & 0.355 & 0.065 & 0.267 & -0.639 \\
GF & $87.2 \%$ & 0.0712 & 0.450 & 0.124 & 0.359 & -0.677 \\
\hline
\end{tabular}

Table 7 shows the results. Comparing Table 6 and Table 7, for each tool, the parameters $m, n$, and $l$ in both equations, Eq. (1) and (3), are the same value, and the coefficient of determination $R^{2}$ and the standard deviation of residual $\sigma$ are also almost the same. Furthermore, in the case of DIA tool, when the values of cutting speed $v$ used in the experiments are substituted in Eq. (3), the value of $k v^{h}$ is 0.2293 to 0.2299 , and the deviation range is only $\pm 0.13 \%$ with respect to the $k$ value of 0.2296 in Eq. (1). Similarly, through the same processing for the case of GF tool, the value of $k v^{h}$ is 0.2053 to 0.2164 , and the deviation range just is \pm $2.85 \%$ relative to the $k$ value of 0.2104 in Eq. (1). Comparing with the variation range of each experimental value of $R_{a}$ in Fig. 4 and Fig. 5, such change rates of the $k v^{h}$ value are very small. In other words, this result has reconfirmed that the cutting speed $v$ is not a significant influence factor on the machining surface roughness. This conclusion is obviously different from that of References [21] and [22]. The reason for the difference can be attributed to the different grain size of graphite materials adopted and the fewer experiment number in these researches.

As a result, the regression equation for estimating the surface roughness $R_{a}$ value can be written as Eq. (4) for DIA tool and Eq. (5) for GF tool.

$$
\begin{aligned}
& R_{a}=0.230 f^{0.355} t^{0.065} s^{0.267} \\
& R_{a}=0.210 f^{0.450} t^{0.124} s^{0.359}
\end{aligned}
$$

4.3 Results of Verification Experiments for the Effect of the Regression Equations In order to further confirm the predication effect of the regression equation, a verification experiment was performed using DIA tool. Table 8 summarizes the results together with the used cutting parameters. In the experiment, the cutting speed, feed rate, and cutting depth were respectively set at 3 or 4 levels different from those used in the initial experiments, and total 28 combinations of cutting condition were arranged. On a workpiece of EDM-3 or EDM-AF5 fine-grained graphite, 28 grooves with the same size shown in Fig. 2 were machined and each one corresponded to a combination of cutting parameter. The surface roughness of workpiece was measured at two separate positions along the bottom surface of each groove machined.

The measured value of surface roughness is written as $R_{a}^{(m)}$ in Table 8. Using the standard deviation of the residual in the regression analysis process for DIA tool explained in 4.2 section, $\sigma=0.0346$, and the $R_{a}$ values estimated by

Table 7: Regression analysis result for Eq. (3) taking cutting speed v into consideration.

\begin{tabular}{cccccccc}
\hline Tool type & $R^{2}$ & Standard error $\sigma$ & $m$ & $n$ & $l$ & $h$ & $\log _{10} k$ \\
\hline DIA & $94.3 \%$ & 0.0347 & 0.355 & 0.065 & 0.267 & -0.004 & -0.630 \\
GF & $87.4 \%$ & 0.0708 & 0.450 & 0.124 & 0.359 & 0.103 & -0.850 \\
\hline
\end{tabular}


Table 8: Result of verification experiments using DIA tool.

\begin{tabular}{|c|c|c|c|c|c|c|c|c|c|}
\hline $\begin{array}{c}\text { Cutting } \\
\text { condition No }\end{array}$ & $\begin{array}{c}f \\
(\mu \mathrm{m} / \text { tooth })\end{array}$ & $\begin{array}{c}v \\
(\mathrm{~m} / \mathrm{min})\end{array}$ & $\begin{array}{c}t \\
(\mathrm{~mm})\end{array}$ & $s(\mu \mathrm{m})$ & $\begin{array}{c}\text { Estimated } \\
R_{a}(\mu \mathrm{m})\end{array}$ & $\begin{array}{l}\text { Measured } \\
R_{a}^{(m)}(\mu m)\end{array}$ & $R_{a}^{(m)} \in \Delta_{1}$ & $R_{a}^{(m)} \in \Delta_{2}$ & $R_{a}^{(m)} \in \Delta_{3}$ \\
\hline \multirow{2}{*}{ No.1 } & \multirow{2}{*}{1.5} & \multirow{2}{*}{94.2} & \multirow{2}{*}{0.05} & \multirow{7}{*}{$\begin{array}{c}5 \\
(\mathrm{EDM}-3)\end{array}$} & \multirow{2}{*}{0.33543} & 0.3844 & $x$ & 0 & 0 \\
\hline & & & & & & 0.3849 & $x$ & 0 & 0 \\
\hline \multirow{2}{*}{ No. 2} & \multirow{2}{*}{6} & \multirow{2}{*}{219.9} & \multirow{2}{*}{0.3} & & \multirow{2}{*}{0.6164} & 0.6578 & 0 & 0 & 0 \\
\hline & & & & & & 0.6597 & 0 & 0 & $\bigcirc$ \\
\hline$\cdots$ & $\begin{array}{c}1.5, \\
6, \\
12, \\
15\end{array}$ & $\begin{array}{c}94.2, \\
219.9, \\
314.2\end{array}$ & $\begin{array}{c}0.05 \\
0.3 \\
0.6\end{array}$ & & $\ldots$ & $\ldots$ & $\ldots$ & $\ldots$ & $\cdots$ \\
\hline \multirow{2}{*}{ No.28 } & \multirow{2}{*}{12} & \multirow{2}{*}{314.2} & \multirow{2}{*}{0.6} & & \multirow{2}{*}{0.8247} & 0.8503 & 0 & 0 & 0 \\
\hline & & & & & & 0.8593 & 0 & 0 & 0 \\
\hline \multirow{2}{*}{ No.29 } & \multirow{2}{*}{15} & \multirow{2}{*}{94.2} & \multirow{2}{*}{0.05} & \multirow{7}{*}{$\begin{array}{c}1 \\
(\text { EDM-AF5) }\end{array}$} & \multirow{2}{*}{0.4942} & 0.4911 & 0 & 0 & 0 \\
\hline & & & & & & 0.5000 & 0 & 0 & 0 \\
\hline \multirow{2}{*}{ No.30 } & \multirow{2}{*}{6} & \multirow{2}{*}{219.9} & \multirow{2}{*}{0.3} & & \multirow{2}{*}{0.4011} & 0.3646 & $x$ & 0 & 0 \\
\hline & & & & & & 0.3739 & 0 & 0 & 0 \\
\hline$\cdots$ & $\begin{array}{c}1.5, \\
6, \\
12, \\
15\end{array}$ & $\begin{array}{c}94.2, \\
219.9, \\
314.2\end{array}$ & $\begin{array}{c}0.05 \\
0.3 \\
0.6\end{array}$ & & $\cdots$ & $\cdots$ & $\cdots$ & $\ldots$ & $\cdots$ \\
\hline \multirow{2}{*}{ No.56 } & \multirow{2}{*}{1.5} & \multirow{2}{*}{314.2} & \multirow{2}{*}{0.6} & & \multirow{2}{*}{0.2565} & 0.2856 & $x$ & 0 & 0 \\
\hline & & & & & & 0.2783 & $\times$ & 0 & 0 \\
\hline \multicolumn{7}{|c|}{ Percentage to total number } & $\begin{array}{l}50 / 112 \\
44.6 \%\end{array}$ & $\begin{array}{l}91 / 112 \\
81.3 \%\end{array}$ & $\begin{array}{c}103 / 112 \\
92.0 \%\end{array}$ \\
\hline
\end{tabular}

Eq. (4) according to each experimental condition, three intervals, $\Delta_{1}, \Delta_{2}$ and $\Delta_{3}$, to evaluate the effect of the regression equation are defined as follows:

$$
\left\{\begin{array}{l}
\Delta_{1}=\left[10^{\log _{10} R^{a}-\sigma}, 10^{\log _{10} R^{a}+\sigma}\right] \\
\Delta_{2}=\left[10^{\log _{10} R^{a}-2 \sigma}, 10^{\log _{10} R^{a}+2 \sigma}\right] \\
\Delta_{3}=\left[10^{\log _{10} R^{a}-3 \sigma}, 10^{\log _{10} R^{a}+3 \sigma}\right]
\end{array}\right.
$$

When one experimental value $R_{a}^{(m)}$ belongs to an interval, the corresponding grid in Table 8 is marked " $\bigcirc$ ", otherwise filled " $\times$ ". For all measured results of $R_{a}$ value in the verification experiment, the percentage of them contained in $\Delta_{1}$, $\Delta_{2}$ and $\Delta_{3}$ are $44.6 \%, 81.3 \%$, and $92.0 \%$, respectively.

A similar verification experiment was also performed using GF tool, EDM-3 and EDM-AF5 graphite workpiece. The experimental results are illustrated in Table 9. In this experiment, the cutting speed and cutting depth were set at 3 levels and the feed rate at 9 levels, respectively. In the machining of each graphite workpiece, 28 combinations of cutting condition were carried out. The three intervals defined by Eq. (6) are determined using the standard deviation of the residual in the regression analysis process for GF tool, $\sigma=0.0712$, and the $R_{a}$ values calculated by Eq. (5). For all measured results of $R_{a}$ value in the verification experiment, the percentage of them contained in $\Delta_{1}, \Delta_{2}$ and $\Delta_{3}$ are $49.1 \%, 79.5 \%$, and $95.5 \%$, respectively.

Compared with the initial experiments described in Chapters 2 and 3 , the range of cutting parameter values adopted in the verification experiments was considerably expanded. Based on the above discussions, therefore, it can be concluded that the results predicted from the regression equations on the surface roughness seems to be appropriate. In other words, the proposed regression equations have good prediction accuracy and reliability for the surface roughness of fine-grained graphite materials milled by the tested tools.

\section{Conclusions}

This paper presents an experimental research on surface roughness of fine-grained graphite by micro milling. Two carbide end mills with or without diamond coating film were used to machine full depth grooves on workpiece made of two types of graphite material with different grain size, EDM-3 and EDM-AF5. Three cutting parameters, cutting speed, feed rate and axial depth of cut, were examined over a wide change range. The influence degree of each cutting parameter, as well as the grain size, on roughness of machined surface was assessed using ANOVA method. The relation between surface roughness and influence factors was derived by the regression analysis and the effect of the regression equations was confirmed by additional verification experiments. The main conclusions can be summarized as follows:

(1) The surface roughness of EDM-AF5 is better and the variation of $R_{a}$ value is smaller than that of EDM-3 significantly. That is, the smaller the grain size of the finegrained graphite material is, the smoother and more beautiful the surfaces machined by micro end mill are.

(2) As carbide micro end mill dedicated to graphite machining, the microcrystalline diamond coated DIA tool 
H. QIU AND A. Kubo

Table 9: Result of verification experiments using GF tool.

\begin{tabular}{|c|c|c|c|c|c|c|c|c|c|}
\hline $\begin{array}{c}\text { Cutting } \\
\text { condition No }\end{array}$ & $\begin{array}{c}f \\
(\mu \mathrm{m} / \text { tooth })\end{array}$ & $\begin{array}{c}v \\
(\mathrm{~m} / \mathrm{min})\end{array}$ & $\begin{array}{c}t \\
(\mathrm{~mm})\end{array}$ & $s(\mu \mathrm{m})$ & $\begin{array}{c}\text { Estimated } \\
R_{a}(\mu \mathrm{m})\end{array}$ & $\begin{array}{l}\text { Measured } \\
R_{a}^{(m)}(\mu m)\end{array}$ & $R_{a}^{(m)} \in \Delta_{1}$ & $R_{a}^{(m)} \in \Delta_{2}$ & $R_{a}^{(m)} \in \Delta_{3}$ \\
\hline \multirow{2}{*}{ No.1 } & \multirow{2}{*}{2.22} & \multirow{2}{*}{56.5} & \multirow{2}{*}{0.6} & \multirow{7}{*}{$\begin{array}{c}5 \\
(\mathrm{EDM}-3)\end{array}$} & \multirow{2}{*}{0.5040} & 0.4321 & 0 & 0 & 0 \\
\hline & & & & & & 0.4558 & $\bigcirc$ & 0 & 0 \\
\hline \multirow{2}{*}{ No. 2} & \multirow{2}{*}{37.5} & \multirow{2}{*}{25.1} & \multirow{2}{*}{0.05} & & \multirow{2}{*}{1.3210} & 1.0182 & $x$ & 0 & 0 \\
\hline & & & & & & 1.0537 & $x$ & $\bigcirc$ & $\bigcirc$ \\
\hline$\cdots$ & $\begin{array}{c}1.67,2.22, \\
5,12.5, \\
16.7,25, \\
33.3,37.5 \\
75\end{array}$ & $\begin{array}{c}25.1 \\
56.5 \\
75.4\end{array}$ & $\begin{array}{c}0.05 \\
0.3 \\
0.6\end{array}$ & & $\cdots$ & $\cdots$ & $\cdots$ & $\cdots$ & $\cdots$ \\
\hline \multirow{2}{*}{ No. 28} & \multirow{2}{*}{12.5} & \multirow{2}{*}{75.4} & \multirow{2}{*}{0.3} & & \multirow{2}{*}{1.0062} & 0.8040 & $x$ & 0 & 0 \\
\hline & & & & & & 0.8330 & $x$ & $\bigcirc$ & $\bigcirc$ \\
\hline \multirow{2}{*}{ No.29 } & \multirow{2}{*}{2.22} & \multirow{2}{*}{56.5} & \multirow{2}{*}{0.05} & \multirow{7}{*}{$\begin{array}{c}1 \\
(\mathrm{EDM}-\mathrm{AF} 5)\end{array}$} & \multirow{2}{*}{0.2078} & 0.1802 & 0 & 0 & 0 \\
\hline & & & & & & 0.1861 & 0 & $\bigcirc$ & 0 \\
\hline \multirow{2}{*}{ No.30 } & \multirow{2}{*}{75} & \multirow{2}{*}{25.1} & \multirow{2}{*}{0.3} & & \multirow{2}{*}{1.2646} & 1.3960 & 0 & 0 & 0 \\
\hline & & & & & & 1.4032 & 0 & $\bigcirc$ & $\bigcirc$ \\
\hline$\cdots$ & $\begin{array}{c}1.67,2.22 \\
5,12.5 \\
16.7,25, \\
33.3,37.5 \\
75\end{array}$ & $\begin{array}{c}25.1, \\
56.5, \\
75.4\end{array}$ & $\begin{array}{c}0.05 \\
0.3 \\
0.6\end{array}$ & & $\cdots$ & $\cdots$ & $\cdots$ & $\cdots$ & $\cdots$ \\
\hline \multirow{2}{*}{ No.56 } & \multirow{2}{*}{25} & \multirow{2}{*}{75.4} & \multirow{2}{*}{0.6} & & \multirow{2}{*}{0.8406} & 0.7179 & 0 & $\bigcirc$ & $\bigcirc$ \\
\hline & & & & & & 0.7138 & $\bigcirc$ & 0 & $\bigcirc$ \\
\hline \multirow{2}{*}{\multicolumn{7}{|c|}{ Percentage to total number }} & $55 / 112$ & $89 / 112$ & $107 / 112$ \\
\hline & & & & & & & $49.1 \%$ & $79.5 \%$ & $95.5 \%$ \\
\hline
\end{tabular}

is more suitable than the non-coating GF tool for surface finish of fine-grained graphite. In the case of DIA tool, not only more smooth and beautiful finish surface but also higher productivity can be achieved in response to the available high cutting speed and feed rate.

(3) For all experimental conditions, the average grain size of graphite material and the feed rate have significant influence on the surface roughness, and the cutting depth has only a minor influence. However, the cutting speed has little effect and thus is not an influence factor.

(4) In factor analysis and quantification analysis of experimental data, the analysis of variance (ANOVA) and the regression analysis are effective tools. The regression equations on the surface roughness obtained in this research present good prediction accuracy and reliability.

\section{References}

[1] Y. Takeuchi, "Micromilling", Journal of the Japan Society for Precision Engineering, Vol.68, No.2, pp.167-170, 2002(In Japanese).

[2] T. Masuzawa, "Micro-EDM", Journal of the Japan Society for Precision Engineering, Vol.68, No.2, pp.180-184, 2002(In Japanese).

IIAE Journal, Vol.8, No.3, 2020
[3] K. H. Ho and S. T. Newman, "State of the art electrical discharge machining (EDM)", International Journal of Machine Tools and Manufacture, Vol.43, No.13, pp.1287-1300, 2003. DOI: 10.1016/S0890-6955(03)00162-7

[4] N. M. Abbas, D. G. Solomon and M. F. Bahari, "A review on current research trends in electrical discharge machining (EDM)", International Journal of Machine Tools and Manufacture, Vol.47, No.7-8, pp.1214-1228, 2007. DOI: 10.1016/j.ijmachtools.2006.08.026

[5] S. Saito and H. Itami, "Advanced die and mold manufacturing technology by utilizations of new types of graphite materials", Machines and Tools, Separate volume of May 2009 issue, pp.8-15, 2009(In Japanese).

[6] F. Klocke, A. Klink, D. Veselovac, D. K. Aspinwall, A. L. Soo, M. Schmidt, J. Schilp, G. Levy and J.-P. Kruth, "Turbomachinery component manufacture by application of electrochemical, electro-physical and photonic processes", CIRP Annals-Manufacturing Technology, Vol.63, No.2, pp.703726, 2014. DOI: 10.1016/j.cirp.2014.05.004

[7] J. Mercer, "Graphite vs. copper", EDM Technical Manual, Poco Graphite, Inc. 2014.

[8] I. Ayesta, B. lzquierdo, J. A. Sánchez, J. M. Ramos, S. Plaza, I. Pombo, N. Ortega, H. Bravo, R. Fradejas and I. Zamakona, "Influence of EDM parameters on slot machining in C1023 aeronautical Alloy", Procedia CIRP, Vol.6, pp.129134, 2013. DOI: 10.1016/j.procir.2013.03.059

[9] E. Uhlmann and D. C. Domingos, "Development and optimization of the die-sinking EDM-technology for machin- 
ing the nickel-based alloy MAR-M247 for turbine components", Procedia CIRP, Vol.6, pp.180-185, 2013. DOI: 10.1016/j.procir.2013.03.102

[10] F. Klocke, M. Holsten, D. Welling, A. Klink and R. Perez, "Influence of Threshold Based Process Control on Sinking EDM of a High Aspect Ratio Geometry in a Gamma Titanium Aluminide", Procedia CIRP, Vol.35, pp.73-78, 2015. DOI: $10.1016 /$ j.procir.2015.08.083

[11] A. Torres, I. Puertas and C. J. Luis, "EDM machinability and surface roughness analysis of INCONEL 600 using graphite electrodes", The International Journal of Advanced Manufacturing Technology, Vol.84, pp.2671-2688, 2016. DOI: 10.1007/s00170-015-7880-x

[12] M. Zeis, "Deformation of thin graphite electrodes with high aspect radio during sinking electrical discharge machining", CIRP Annals-Manufacturing Technology, Vol.66, No.1, pp.185-188, 2017. DOI: 10.1016/j.cirp.2017.04.139

[13] O. Flaño, I. Ayesta, B. Izquierdo, J. A. Sánchea, Y. Zhao and M. Kunieda, "Improvement of EDM performance in high-aspect radio slot machining using multi-holed electrodes”, Precision Engineering, Vol.51, pp.223-231, 2018. DOI: $10.1016 /$ j.precisioneng.2017.08.014

[14] R. B. Schroeter, R. Kratochvil and J. O. Gomes, "High-speed finishing milling of industrial graphite electrodes", Journal of Materials Processing Technology, Vol.179, No.1-3, pp.128-132, 2006. DOI: 10.1016/j.jmatprotec.2006.03.076

[15] L. Zhou, C. Y. Wang and Z. Qin, "Tool wear characteristics in high-speed milling of graphite using a coated carbide micro endmill", Proceedings of the Institution of Mechanical Engineers Part B: Journal of Engineering Manufacture, Vol.223, No.3, pp.267-277, 2009. DOI: 10.1243/09544054JEM1326

[16] M. Hashimoto, K. Kanda and T. Tsubokawa, "Reduction of diamond-coated cutting tool wear during graphite cutting”, Precision Engineering, Vol.51, pp.186-189, 2018. DOI: $10.1016 /$ j.precisioneng.2017.08.009

[17] C. Wang, "High-speed milling of graphite electrode with endmill of small diameter", Chinese Journal of Mechanical Engineering, Vol.20, No.4, pp.27-31, 2007. DOI: 10.3901/CJME.2007.04.027

[18] G. Mijušković, P. Krajnik and J. Kopač, "Analysis of tool deflection in micro milling of graphite electrodes", The International Journal of Advanced Manufacturing Technology, Vol.76, pp.209-217, 2015. DOI: 10.1007/s00170-013-55362

[19] Z. Wan, D. Yang, L. Lu, J. Wu and Y. Tang, "Mechanism of material removal during orthogonal cutting of graphite/polymer composites", The International Journal of Advanced Manufacturing Technology, Vol.82, pp.18151821, 2016. DOI: 10.1007/s00170-015-7458-7

[20] Y.-K. Yang, M.-T. Chuang and S.-S. Lin, "Optimization of dry machining parameters for high-purity graphite in end milling process via design of experiments methods", Journal of Materials Processing
Technology, Vol.209, No.9, pp.4395-4400, 2009. DOI: 10.1016/j.jmatprotec.2008.11.021

[21] D. Huo, C. Lin and K. Dalgarno, "An experimental investigation on micro machining of fine-grained graphite", The International Journal of Advanced Manufacturing Technology, Vol.72, pp.943-953, 2014. DOI: 10.1007/s00170-014-5730$\mathrm{x}$

[22] O. S. López, A. R. González and I. H. Castillo, "Statistical analysis of surface roughness of machined graphite by means of CNC milling", Ingenier-ía e Investigación, Vol.36, No.3, pp.89-94, 2016. DOI: 10.15446/ing.investig.v36n3.53603

[23] Transforming the world through poco materials, Entegris, http://www.poco.com/Home.aspx, access date: 2019.12.

[24] JIS B4053:2013, "Classification and Application of Hard Cutting Materials for Metal Removal with Defined Cutting Edges-Designation of the Main Groups and Groups of Application", Japanese Standards Association.

[25] Y. Kita, "Data Analysis and SPSS 2: Development", Hokuju Shuppan, Inc. p.175, 2006(In Japanese).

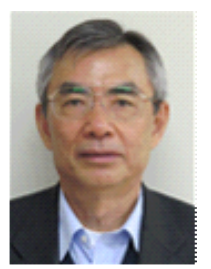

Hua Qiu (Member) is a professor in the Mechanical Engineering Department of Kyushu Sangyo University, Japan. He received a BS in Mechanical Engineering from Chongqing University, China, an MS and a Ph.D. in Mechanical Engineering from Kyushu University, Japan, in 1982, 1986 and 1989, respectively. His current research activities mainly focus on precision machining and measurement of complex contour, detection and diagnosis for motion accuracy of machine tool, and optimal design of mechanism. He is a member of the Japan Society of Mechanical Engineers, the Japan Society for Precision Engineering and Japan Society for Design Engineering.

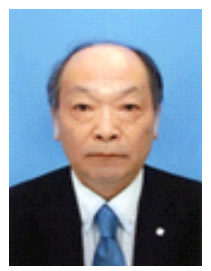

Akio Kubo (Member) received B.E. degree in Mechanical Engineering from Hiroshima University, Hiroshima, Japan, in 1986, and M.E. and Dr.Eng. degrees from Kyushu Sangyo University, Fukuoka, Japan, in 1990, and 2009, respectively. He is an associate professor in the Department of Mechanical Engineering at Kyushu Sangyo University. His research field is gear manufacture. He is a member of the Japan Society of Mechanical Engineers, the Japan Society for Precision Engineering and Japan Society for Design Engineering. 